\title{
Beneficial effect of risedronate for preventing recurrent hip fracture in the elderly Japanese women
}

\author{
M. Osaki $\cdot$ K. Tatsuki $\cdot$ T. Hashikawa $\cdot$ T. Norimatsu . \\ K. Chiba $\cdot$ S. Motokawa $\cdot$ I. Furuichi $\cdot$ Y. Doiguchi $\cdot$ \\ K. Aoyagi $\cdot$ H. Shindo
}

Received: 12 June 2010 / Accepted: 13 January 2011 / Published online: 11 March 2011

(C) The Author(s) 2011. This article is published with open access at Springerlink.com

\begin{abstract}
Summary A 36-month observational study compared the incidence of unaffected side hip fracture in Japanese female osteoporosis patients with a history of hip fracture between 173 patients receiving risedronate and 356 risedronateuntreated controls. New hip fractures were significantly less frequent in the risedronate group, suggesting a preventive effect in high-risk patients.

Introduction The purpose of this study was to investigate the preventive effect of risedronate on second hip fracture immediately following a first hip fracture in Japanese female osteoporosis patients with unilateral hip fracture. Methods We conducted a prospective matched cohort study in 184 patients treated with risedronate and 445 patients not receiving risedronate after discharge from hospital. Both groups were followed-up for 36 months, and the incidence of unaffected side hip fracture and the frequency of adverse events were assessed.

Results Efficacy could be investigated in 173 patients from the risedronate group and 356 patients from the control
\end{abstract}

M. Osaki $(\bowtie) \cdot$ T. Hashikawa $\cdot$ T. Norimatsu $\cdot$ K. Chiba

H. Shindo

Department of Orthopaedic Surgery, Nagasaki University

Graduate School of Biomedical Sciences,

1-7-1 Sakamoto,

Nagasaki 852-8501, Japan

e-mail: mosaki@nagasaki-u.ac.jp

K. Tatsuki

Takeda Pharmaceutical Company Limited,

1-1, Doshomachi 4-Chome, Chuo-ku,

Osaka 540-8645, Japan

S. Motokawa

Department of Orthopaedic Surgery,

National Hospital Organization Nagasaki Medical Center,

Kubara 2-1001-1 Omura,

Nagasaki 856-8562, Japan group. Hip fracture was detected in 5 and 32 patients, respectively. Kaplan-Meier estimates of the 36-month fracture incidence were $4.3 \%$ in the risedronate group and $13.1 \%$ in the control group $(P=0.010$, log-rank test $)$. The hazard ratios (95\% confidence intervals) obtained by univariate and multivariate analysis were 0.310 (0.121$0.796)$ and $0.218(0.074-0.639)$, respectively, indicating a significantly lower incidence of unaffected side hip fracture in the risedronate group. Adverse events occurred in 38 patients (48 events) from the risedronate group and 94 patients (108 events) from the control group, with serious adverse events in 21 patients (26 events) and 78 patients (88 events), respectively.

Conclusions No significant differences were observed between the two groups. The incidence of unaffected side hip fracture was significantly lower in the risedronate group. Accordingly, risedronate may have a preventive effect on hip fracture in high-risk Japanese female osteoporosis patients for fracture with a history of unilateral hip fracture.

I. Furuichi

Department of Orthopaedic Surgery, Ureshino Medical Center, 2436, Ureshino-machi, Shimojuku, Ureshino-shi,

Saga 843-0393, Japan

Y. Doiguchi

Department of Orthopaedic Surgery, Nagasaki Rosai Hospital, 2-12-5. Setogoe, Sasebo-shi,

Nagasaki 857-0134, Japan

T. Hashikawa $\cdot$ T. Norimatsu $\cdot$ K. Aoyagi

Department of Public Health, Nagasaki University Graduate

School of Biomedical Sciences,

1-12-4 Sakamoto,

Nagasaki 852-8523, Japan 
Keywords Bisphosphonate $\cdot$ Hip fracture $\cdot$ Matched cohort study $\cdot$ Osteoporosis $\cdot$ Risedronate

\section{Introduction}

Osteoporosis is defined as "a skeletal disease characterized by loss of bone strength susceptible to increased risk of fracture", which is frequent in women and the elderly [1]. According to the current WHO diagnostic criteria [2], the number of osteoporosis patients in USA is estimated to be 5.3 million [3], while the 2006 Japanese guideline estimates the number of Japanese patients as 7.8 to 11 million [4].

The objective of treating osteoporosis is to prevent the occurrence of fracture. Among the fractures attributable to osteoporosis, hip fracture has the most important influence on survival, quality of life, and medical costs. The worldwide incidence of hip fracture is expected to increase from approximately 1.5 million in 1990 to $4.5-6.3$ million in 2050 [5, 6]. The number of hip fractures in Japan was estimated to be 148,100 in 2007 , and this has increased every year since the start of investigation in 1987 [7].

Prior fracture is a risk factor for new fractures in addition to sex, age, and low bone mineral density (BMD) [8]. In particular, patients with a history of hip fracture may have an increased risk of unaffected side hip fracture because of excessive weight bearing on the opposite side while walking due to anxiety about recurrence.

Current drug treatment for osteoporosis has made considerable progress. Risedronate is a bisphosphonate that is employed in patients with osteoporosis, which reduces bone resorption and bone turnover by inhibiting osteoclast activity [9]. Risedronate has been shown to increase BMD [10, 11], and to inhibit the occurrence of vertebral compression fractures $[12,13]$ as well as hip fractures $[14,15]$. Based on such evidence, it is considered that risedronate is one of the most effective treatments for osteoporosis currently available [16].

Only a few studies on the efficacy of risedronate for inhibiting hip fracture in specific Japanese patient group have been performed so far $[17,18]$. In addition, although patients with a history of hip fracture have a higher risk of new hip fractures, a study has not been conducted in this patient population. Accordingly, we conducted a prospective matched cohort study in Japanese osteoporosis patients with a history of hip fracture.

\section{Methods}

Study design and subjects

This study was conducted in female Japanese patients at Nagasaki University hospital and 16 affiliated institutions (17 institutions in total). The enrollment period was from July 2003 to June 2006, and the study finished in June 2009.

All patients who underwent hip fracture surgery at the participating institutions and were discharged during the enrollment period were tentatively enrolled by uploading data to a web page. The enrollment items were sex, age, height, body weight, body mass index (BMI), presence/absence of osteoporosis, presence/absence of vertebral fracture, site of hip fracture surgery, date of injury, date of hospitalization, treatment of the fracture, address at the time of injury, postoperative period, independence rating before injury, independence rating at discharge, drug treatment for osteoporosis at discharge, past history at discharge, complications at discharge, BMD, and possibility/impossibility of outpatient follow-up. The attending physician explained the purpose and methods of this study to each patient. We specified Japanese criteria for the diagnosis of osteoporosis according to the diagnostic standard for primary osteoporosis (2000 revised edition) of the Japanese Society for Bone and Mineral Research [19]. The exclusion criteria were as follows: (1) no diagnosis of primary osteoporosis according to the above criteria, (2) bilateral hip fracture, (3) prior history of hip fracture, (4) patients discharged death, and (5) patients who could not be followed-up after discharge.

Out of the preliminary enrolled patients, those treated with risedronate at the approved Japanese dose of $2.5 \mathrm{mg} /$ day (Benet ${ }^{\circledR} 2.5 \mathrm{mg}$; Takeda Pharmaceutical Co., Ltd, Osaka, Japan) at the initial visit after discharge on the judgment of the physician in charge were included in the administration group. Following the initial outpatient visit after discharge from hospital, patients were enrolled by uploading the required data to the web page.

After enrollment of patients in the group receiving risedronate, the patient enrollment center selected all of the matching patients as candidates for the control group. The demographic data and other items used for matching the groups are listed in Appendix 1. Patients in the control group were not being treated with any bisphosphonate preparation and the required data was uploaded as the control group to the web page (Fig. 1).

The duration of the study was 36 months from the initial outpatient visit after discharge from hospital, and data from case report forms were uploaded to the web page every 6 months. The items assessed included the presence/ absence of unaffected side hip fracture and the date of occurrence, adverse events, compliance with medication, other drugs for the treatment of osteoporosis, drugs for the treatment of complications, other concomitant therapy, independence rating, bone metabolism markers, BMD, and new clinical fractures.

The study was discontinued if patients satisfied any of the following criteria for discontinuation; failure to attend, refusal of treatment, discontinuation of risedronate or 


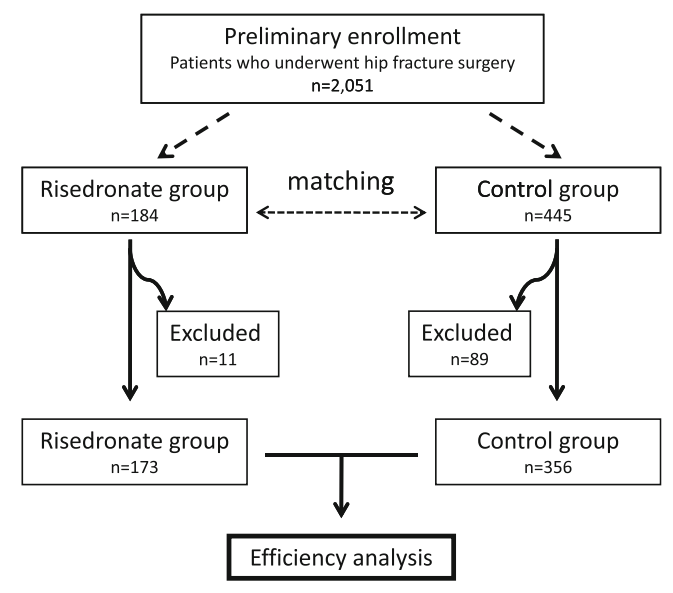

Fig. 1 Disposition of the patients. Of the 2,051 patients who underwent preliminary enrollment, 1,142 patients were ineligible, and 280 patients were excluded from enrollment for several reasons. Among the rest, 184 patients were taking risedronate at the initial outpatient visit after discharge. Four hundred forty-five patients were matched with patients with taking risedronate. Then, 11 patients from the risedronate group and 89 patients from the control group were excluded because it was impossible to follow-up after initial visit, leaving 529 patients (173 in the risedronate group and 356 in the control group) for efficacy analysis

switching to another bisphosphonate (risedronate group only), starting treatment with a bisphosphonate (control group only), and occurrence of adverse events. For the discontinued/dropout patients, the presence/absence of fractures until the discontinued/dropout date were determined. In addition, the incidence of unaffected side hip fracture during the period from the discontinued/dropout date to 3 years after the initial outpatient visit was investigated separately.

This survey was a post-marketing surveillance conducted according to the Japanese Good Post-Marketing Surveillance Practice (GPMSP) and Good Post-Marketing Study Practice (GPSP) ordinances. The GPMSP and GPSP ordinances specify items that are to be strictly complied with in order to achieve appropriate post-marketing surveillance and studies of drugs. According to these ordinances, a post-marketing survey is to be conducted in accordance with the approved indications and during routine medical practice. As described above, risedronate was administered according to the judgment of the attending physician and in compliance with the abovementioned conditions. To minimize the resulting bias, demographic factors showing significant intergroup differences were adjusted by multivariate analysis.

\section{Treatment}

Patients in the risedronate group took a Benet ${ }^{\circledR} 2.5 \mathrm{mg}$ tablet orally once daily at the time of awakening with water (approximately $180 \mathrm{~mL}$ ). If administration of risedronate was discontinued or switched to another bisphosphonate, the study was discontinued.

Statistical analysis

All of the patients enrolled were analyzed for safety, while those in whom the status of the unaffected side hip was confirmed at least once after the start of the study were assessed for efficacy. Patients demographic factors (age, BMI, site of hip fracture surgery, etc.) were totaled for each group, and intergroup comparison was performed. The incidence of unaffected side hip fracture was estimated by the KaplanMeier method, and differences were investigated by the logrank test. Univariate and multivariate analyses were done with known risk factors for hip fracture (age, and BMI [20]) and demographic factors showing significant intergroup differences as the explanatory variables to estimate the hazard ratios for unaffected side hip fracture after adjustment for these variables. Adverse events were totaled in each group, and intergroup differences were investigated by using Fisher's exact test. All statistical analyses were performed with SAS 9.1.3 software. The level of significance and the confidence interval were $P \leq$ 0.05 (bilateral) and 95\% (bilateral), respectively.

\section{Results}

Characteristics of the patients and follow-up

Of the 2,051 patients who underwent hip fracture surgery and following preliminary enrollment, 184 patients were taking risedronate at the initial outpatient visit after discharge. A total of 445 patients were matched with the patients taking risedronate. Then, 11 patients from the risedronate group and 89 patients from the control group were excluded because it was impossible to follow-up after initial visit, leaving 529 patients (173 in the risedronate group and 356 in the control group) for efficacy analysis (Fig. 1).

The age and BMI (mean \pm standard deviation) at the time of discharge were $80.2 \pm 7.9$ years and $21.00 \pm 3.64 \mathrm{~kg} / \mathrm{m}^{2}$, respectively, in the risedronate group versus $81.9 \pm 8.0$ years and $20.66 \pm 3.32 \mathrm{~kg} / \mathrm{m}^{2}$ in the control group. The site of hip fracture surgery was either medial or lateral in nearly half of the patients each, and the most frequent method of treatment was surgical osteosynthesis. Concerning the treatment for osteoporosis at the time of discharge from hospital, the use of bisphosphonates was significantly more frequent in the risedronate group (27.2\%) than in the control group (2.5\%) $(P<0.001)$. With regard to vitamin $\mathrm{D}_{3}$ administration, no significant differences were observed between the two groups at discharge or at the initial outpatient visit. 
Table 1 Patient demographic data (efficacy analysis set)

\begin{tabular}{|c|c|c|c|c|}
\hline & & \multicolumn{2}{|l|}{ Group } & \multirow[t]{2}{*}{$P$ value } \\
\hline & & $\begin{array}{l}\text { Risedronate } \\
\text { group }\end{array}$ & Control group & \\
\hline \multicolumn{2}{|l|}{ Number of patients } & 173 & 356 & \\
\hline Age (at discharge) & Mean (SD) & $80.2(7.9)$ & $81.9(8.0)$ & $P=0.004$ \\
\hline BMI (at discharge) & Mean (SD) & $21.00(3.64)$ & $20.66(3.32)$ & $P=0.636$ \\
\hline \multirow[t]{3}{*}{ Site of hip fracture } & Medial & $95(54.9 \%)$ & $167(46.9 \%)$ & $P=0.072$ \\
\hline & Lateral & $77(44.5 \%)$ & $189(53.1 \%)$ & \\
\hline & Bilateral & $1(0.6 \%)$ & $0(0.0 \%)$ & \\
\hline \multirow[t]{3}{*}{ Treatment } & Osteosynthesis & $114(65.9 \%)$ & $248(69.7 \%)$ & $P=0.327$ \\
\hline & Femoral head replacement & $58(33.5 \%)$ & $102(28.7 \%)$ & \\
\hline & Conservative therapy & $1(0.6 \%)$ & $6(1.7 \%)$ & \\
\hline \multirow[t]{11}{*}{ Drug treatment for osteoporosis at discharge } & Present & $66(38.2 \%)$ & $72(20.2 \%)$ & $P<0.001$ \\
\hline & Ca preparation & $3(1.7 \%)$ & $5(1.4 \%)$ & $P=0.720$ \\
\hline & VD3 preparation & $16(9.2 \%)$ & $54(15.2 \%)$ & $P=0.075$ \\
\hline & VK2 preparation & $2(1.2 \%)$ & $4(1.1 \%)$ & $P=1.000$ \\
\hline & Calcitonin preparation & $3(1.7 \%)$ & $2(0.6 \%)$ & $P=0.336$ \\
\hline & $\begin{array}{l}\text { Female hormone } \\
\text { preparation }\end{array}$ & $0(0.0 \%)$ & $0(0.0 \%)$ & - \\
\hline & Others & $0(0.0 \%)$ & $4(1.1 \%)$ & $P=0.309$ \\
\hline & $\begin{array}{l}\text { Bisphosphonate } \\
\text { preparation }\end{array}$ & $47(27.2 \%)$ & $9(2.5 \%)$ & $P<0.001$ \\
\hline & Risedronate & $46(26.6 \%)$ & $5(1.4 \%)$ & $P<0.001$ \\
\hline & Alendronate & $1(0.6 \%)$ & $3(0.8 \%)$ & $P=1.000$ \\
\hline & Didronel & $0(0.0 \%)$ & $1(0.3 \%)$ & $P=1.000$ \\
\hline \multirow[t]{8}{*}{ Complications at discharge } & Present & $132(76.3 \%)$ & $315(88.5 \%)$ & $P<0.001$ \\
\hline & Cardiac disease & $44(25.4 \%)$ & $129(36.2 \%)$ & $P=0.014$ \\
\hline & Diabetes & $14(8.1 \%)$ & $41(11.5 \%)$ & $P=0.288$ \\
\hline & Hypertension & $98(56.6 \%)$ & $215(60.4 \%)$ & $P=0.451$ \\
\hline & Hyperlipidemia & $24(13.9 \%)$ & $29(8.1 \%)$ & $P=0.045$ \\
\hline & Dementia & $31(17.9 \%)$ & $141(39.6 \%)$ & $P<0.001$ \\
\hline & Parkinson's disease & $2(1.2 \%)$ & $16(4.5 \%)$ & $P=0.070$ \\
\hline & Gastrointestinal disease & $34(19.7 \%)$ & $77(21.6 \%)$ & $P=0.650$ \\
\hline \multirow{7}{*}{$\begin{array}{l}\text { Drug treatment for osteoporosis at the initial visit after } \\
\text { discharge }\end{array}$} & Present & $34(19.7 \%)$ & $54(15.2 \%)$ & $P=0.214$ \\
\hline & Ca preparation & $7(4.0 \%)$ & $6(1.7 \%)$ & $P=0.133$ \\
\hline & VD3 preparation & $28(16.2 \%)$ & $45(12.6 \%)$ & $P=0.284$ \\
\hline & VK2 preparation & $0(0.0 \%)$ & $5(1.4 \%)$ & $P=0.178$ \\
\hline & Calcitonin preparation & $1(0.6 \%)$ & $4(1.1 \%)$ & $P=1.000$ \\
\hline & $\begin{array}{l}\text { Female hormone } \\
\text { preparation }\end{array}$ & $0(0.0 \%)$ & $0(0.0 \%)$ & - \\
\hline & Others & $0(0.0 \%)$ & $3(0.8 \%)$ & $P=0.554$ \\
\hline \multirow[t]{5}{*}{ Independence rating at the initial visit after discharge } & Independent gait & $21(12.1 \%)$ & $33(9.3 \%)$ & $P=0.011$ \\
\hline & Cane walk & $106(61.3 \%)$ & $176(49.4 \%)$ & \\
\hline & Walker & $15(8.7 \%)$ & $58(16.3 \%)$ & \\
\hline & Wheelchair & $31(17.9 \%)$ & $84(23.6 \%)$ & \\
\hline & Bedridden & $0(0.0 \%)$ & $5(1.4 \%)$ & \\
\hline
\end{tabular}

$B M I$ body mass index, $S D$ standard deviation, $C a$ calcium, $V D 3$ vitamin $\mathrm{D}_{3}$, VK2 vitamin $\mathrm{K}_{2}$ 
Regarding complications at discharge, there was a significant difference between the two groups with respect to cardiac disease (risedronate group: $25.4 \%$; control group: $36.2 \%, P=$ $0.014)$, hyperlipidemia $(13.9 \%$ versus $8.9 \%, P=0.045)$, and dementia $(17.9 \%$ versus $39.6 \%, P<0.001)$. With regard to other drugs being taken for the treatment for osteoporosis (excluding risedronate) at the initial outpatient visit after discharge, no significant differences were observed between the two groups. The independence rating was significantly higher in the risedronate group $(P=0.011)$ (Table 1$)$.

\section{Compliance}

In the risedronate group, the compliance rate with treatment was " $90 \%$ or higher" throughout the study in most patients, and this was a high level of compliance.

Incidence of unaffected side hip fracture

Unaffected side hip fracture occurred in 5 patients from the risedronate group and 32 patients from the control group. The 36-month incidence was estimated to be $4.3 \%$ in the risedronate group and $13.1 \%$ in the control group, with a significant difference between the two groups $(P=0.010$, log-rank test). The hazard ratio calculated by univariate analysis was 0.310 , indicating a $69 \%$ decrease in the risk of unaffected side hip fracture in the risedronate group (Fig. 2).

Multivariate analysis was also done using age, BMI, and demographic factors with significant intergroup differences as explanatory variables, and the adjusted hazard ratio was estimated to be 0.218 , also indicating a significantly lower risk of unaffected side hip fracture in the risedronate group $(P=0.006)$ (Table 2).

\section{Bone mineral density}

Bone mineral density of the lumbar spine (second to fourth lumbar spine BMD) at the start of the study was $0.7105 \pm$ $0.1834\left(\mathrm{~g} / \mathrm{cm}^{2}\right)$ in the risedronate group, and $0.6220 \pm$ $0.1594\left(\mathrm{~g} / \mathrm{cm}^{2}\right)$ in the control group, showing no significant difference between the two groups $(P=0.110)$.

\section{Adverse events}

Adverse events occurred in 38 patients (20.7\%, 48 events) from the risedronate group and 94 patients $(21.1 \%, 108$ events) from the control group. These events were serious in 21 patients $(11.4 \%, 26$ events) from the risedronate group and 78 patients $(17.5 \%, 88$ events) from the control group. No significant differences were observed between the two groups. The most frequent adverse event in the risedronate group was gastrointestinal disorders (13 events, 7.1\%), and such disor- ders were significantly $(P<0.001)$ more frequent than in the control group (three events, $0.7 \%$ ).

Hip fracture occurred in 34 patients $(7.6 \%)$ from the control group, showing a significantly $(P=0.002)$ higher incidence than in the risedronate group (three patients, $1.6 \%$ ) (Table 3).

\section{Discussion}

In this study, the incidence of unaffected side hip fracture was compared between Japanese female osteoporosis patients who were followed-up after surgery for hip fracture with or without risedronate treatment. The incidence of unaffected side hip fracture was significantly lower in the risedronate group than the control group, suggesting a preventive effect of risedronate on hip fracture in these high-risk patients.

According to recent reports [21,22], the incidence of hip fracture is decreasing in Europe and the USA. However, it is anticipated that the worldwide incidence of hip fracture will continue to increase considering the aging of the population. For example, another study [23] has shown that the incidence of hip fracture is still increasing in Japan. Taking the speed of population aging into consideration, prevention of hip fracture is an urgent issue for Japanese health policy.

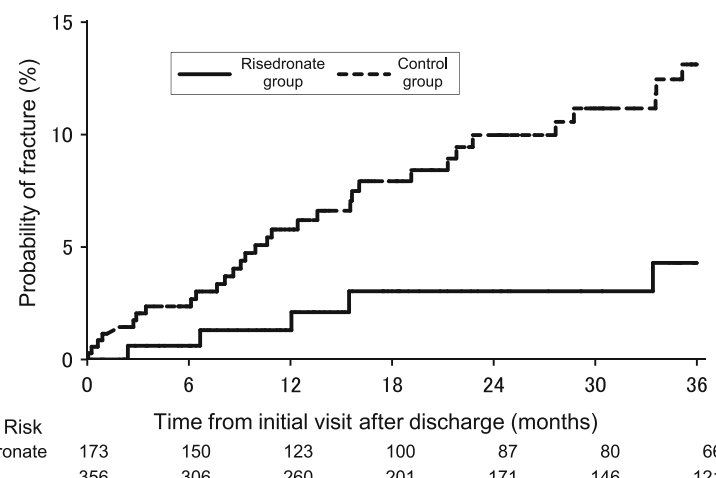

$\begin{array}{lrrrrrrr}\text { Risedronate } & 173 & 150 & 123 & 100 & 87 & 80 & 66\end{array}$

\begin{tabular}{cccccccc}
\hline Group & $N$ & \multicolumn{2}{c}{$\begin{array}{c}\text { Number of } \\
\text { patients with } \\
\text { fracture }\end{array}$} & $\begin{array}{c}\text { 3-year } \\
\text { occurrence } \\
\text { rate }\end{array}$ & $\begin{array}{c}\text { Cox regression } \\
\text { HR }(95 \% \mathrm{Cl})\end{array}$ & $\begin{array}{c}\text { Log-rank test } \\
\text { P value }\end{array}$ \\
\cline { 2 - 6 } Total & Medial & Lateral & & \\
\hline $\begin{array}{c}\text { Risedronate } \\
\text { group }\end{array}$ & 173 & 5 & 4 & 1 & $4.3 \%$ & $0.310(0.121,0.796)$ & \\
$\begin{array}{c}\text { Control } \\
\text { group }\end{array}$ & 356 & 32 & 13 & 19 & $13.1 \%$ & Reference & \\
\hline
\end{tabular}

Fig. 2 Kaplan-Meier curves for the occurrence of unaffected side hip fracture (efficacy analysis set). Unaffected side hip fracture occurred in five patients from the risedronate group and 32 patients from the control group. The 36-month incidence was estimated to be $4.3 \%$ in the risedronate group and $13.1 \%$ in the control group, with a significant difference between the two groups $(P=0.010$, log-rank test). The hazard ratio calculated by univariate analysis was 0.310 , indicating a $69 \%$ decrease in the risk of unaffected side hip fracture in the risedronate group 
Table 2 Cox regression analysis of unaffected-side hip fracture (efficacy analysis set)

\begin{tabular}{|c|c|c|c|c|c|c|}
\hline \multirow[b]{2}{*}{ Explanatory variable } & \multirow[b]{2}{*}{ Category } & \multirow[b]{2}{*}{$\mathrm{N}$} & \multicolumn{2}{|l|}{ Univariate } & \multicolumn{2}{|l|}{ Multivariate } \\
\hline & & & HR estimate $(95 \% \mathrm{CI})$ & $P$ value & HR estimate $(95 \% \mathrm{CI})$ & $P$ value \\
\hline \multirow[t]{2}{*}{ Group } & Control group & 356 & Reference & & Reference & \\
\hline & Risedronate group & 173 & $0.310(0.121,0.796)$ & 0.015 & $0.218(0.074,0.639)$ & 0.006 \\
\hline \multirow[t]{4}{*}{ Age (at discharge) } & $\leq 69$ & 34 & Reference & & Reference & \\
\hline & $70-79$ & 151 & $0.311(0.084,1.160)$ & 0.082 & $0.303(0.077,1.196)$ & 0.088 \\
\hline & $80-89$ & 273 & $1.060(0.369,3.041)$ & 0.914 & $0.993(0.309,3.185)$ & 0.990 \\
\hline & $\geq 90$ & 71 & $0.319(0.058,1.743)$ & 0.187 & $0.278(0.045,1.725)$ & 0.169 \\
\hline \multirow[t]{3}{*}{ BMI (at discharge) } & Lower than 20 & 217 & Reference & & Reference & \\
\hline & 20 or higher to lower than 25 & 255 & $0.474(0.237,0.947)$ & 0.035 & $0.507(0.250,1.029)$ & 0.060 \\
\hline & 25 or higher & 57 & $0.462(0.138,1.549)$ & 0.211 & $0.539(0.154,1.891)$ & 0.334 \\
\hline \multirow[t]{2}{*}{ Drug treatment for osteoporosis (at discharge) } & Nonuse & 391 & Reference & & Reference & \\
\hline & Use & 138 & $0.902(0.436,1.864)$ & 0.780 & $0.869(0.328,2.305)$ & 0.778 \\
\hline \multirow[t]{2}{*}{ Bisphosphonate therapy (at discharge) } & Nonuse & 473 & Reference & & Reference & \\
\hline & Use & 56 & $1.144(0.445,2.937)$ & 0.780 & $2.728(0.695,10.706)$ & 0.150 \\
\hline \multirow[t]{2}{*}{ Complications (at discharge) } & Absent & 82 & Reference & & Reference & \\
\hline & Present & 447 & $0.909(0.379,2.178)$ & 0.830 & $0.850(0.303,2.384)$ & 0.758 \\
\hline \multirow[t]{2}{*}{ Cardiac disease (at discharge) } & Absent & 356 & Reference & & Reference & \\
\hline & Present & 173 & $1.092(0.556,2.145)$ & 0.798 & $0.969(0.468,2.010)$ & 0.933 \\
\hline \multirow[t]{2}{*}{ Dementia (at discharge) } & Absent & 357 & Reference & & Reference & \\
\hline & Present & 172 & $1.555(0.807,2.999)$ & 0.187 & $1.522(0.714,3.244)$ & 0.277 \\
\hline \multirow[t]{3}{*}{ Independence rating (at the initial visit) } & Independent/stick & 336 & Reference & & Reference & \\
\hline & Walker & 73 & $0.389(0.092,1.636)$ & 0.198 & $0.296(0.069,1.275)$ & 0.102 \\
\hline & Wheelchair/bedridden & 120 & $1.036(0.470,2.284)$ & 0.929 & $0.872(0.369,2.060)$ & 0.755 \\
\hline
\end{tabular}

$B M I$ body mass index, $H R$ hazard ratio, $C I$ confidence interval

There have only been two large-scale clinical studies with the primary endpoint of hip fracture, i.e., the HIP study [14] and the HORIZON study evaluating the effect of zoledronate [24], and both were placebo-controlled studies. Although there is sufficient evidence of a preventive effect on hip fracture for various drugs, adequate information is not available about their relative efficacy and safety [16]. This study showed that risedronate can prevent new hip fractures in patients with a history of hip fracture, i.e., a high-risk population. It provides useful information for determining the management of osteoporosis.

A subgroup analysis of patients with osteoporosis aged 70 years or older [15] from the HIP study evaluated the efficacy of risedronate for preventing hip fracture [14] and demonstrated that the 36-month incidence of hip fracture was $7.4 \%$ in the placebo group versus $3.8 \%$ in the risedronate group, with the relative risk being 0.54 . In the present study, the 36-month incidence of unaffected side hip fracture was $13.1 \%$ in the control group versus $4.3 \%$ in the risedronate group (hazard ratio: 0.31), indicating a similar preventive effect, although the incidence of fracture was higher in our two groups. These results suggest that risedronate can prevent new fractures even in patients in the high-risk groups with the history of fracture caused by osteoporosis. It is likely that the higher incidence of fracture in the present study can be attributed to the enrollment of patients who had already suffered from hip fracture.

Regarding the efficacy of risedronate for inhibiting hip fracture in Japanese population, the Sato $\mathrm{Y}$ et al. reported the preventive effect of risedronate and ergocalciferol plus calcium supplementation in Japanese women with Alzheimer's disease [17]. They also reported the preventive effect of risedronate in Japanese men after stroke [18]. Although they presented the preventive effect of risedronate on hip fracture, the objective of these studies are limited to the specific Japanese patient group. In addition, although patients with a history of hip fracture have a 
Table 3 Adverse events (safety analysis set)

\begin{tabular}{|c|c|c|c|}
\hline \multirow{2}{*}{$\begin{array}{l}\text { Adverse event } \\
\text { ( } 1 \% \text { or higher in either group) }\end{array}$} & \multicolumn{2}{|l|}{ Group } & \multirow{2}{*}{$\begin{array}{l}P \text { value } \\
\text { (Fisher's exact test) }\end{array}$} \\
\hline & Risedronate group & Control group & \\
\hline No. of patients & 184 & 445 & \\
\hline Number of patients with adverse events & $38(20.7 \%)$ & $94(21.1 \%)$ & $P=1.000$ \\
\hline Number of adverse event & 48 & 108 & \\
\hline Number of patients with serious adverse events & $21(11.4 \%)$ & $78(17.5 \%)$ & $P=0.070$ \\
\hline Number of serious adverse events & 26 & 88 & \\
\hline Cardiac disorders & $2(1.1 \%)$ & $3(0.7 \%)$ & $P=0.633$ \\
\hline Gastrointestinal disorders & $13(7.1 \%)$ & $3(0.7 \%)$ & $P<0.001$ \\
\hline Epigastric pain & $2(1.1 \%)$ & $0(0.0 \%)$ & $P=0.085$ \\
\hline Constipation & $3(1.6 \%)$ & $1(0.2 \%)$ & $P=0.078$ \\
\hline Gastritis & $3(1.6 \%)$ & $0(0.0 \%)$ & $P=0.025$ \\
\hline General disorders and administration site conditions & $3(1.6 \%)$ & $7(1.6 \%)$ & $P=1.000$ \\
\hline Death & $1(0.5 \%)$ & $7(1.6 \%)$ & $P=0.448$ \\
\hline Infections and infestations & $3(1.6 \%)$ & $9(2.0 \%)$ & $P=1.000$ \\
\hline Pneumonia & $1(0.5 \%)$ & $6(1.3 \%)$ & $P=0.680$ \\
\hline Injury, poisoning and procedural complications & $11(6.0 \%)$ & $60(13.5 \%)$ & $P=0.006$ \\
\hline Hip fracture & $3(1.6 \%)$ & $34(7.6 \%)$ & $P=0.002$ \\
\hline Radius fracture & $2(1.1 \%)$ & $1(0.2 \%)$ & $P=0.206$ \\
\hline Spinal compression fracture & $2(1.1 \%)$ & $9(2.0 \%)$ & $P=0.523$ \\
\hline Musculoskeletal and connective tissue disorders & $3(1.6 \%)$ & $3(0.7 \%)$ & $P=0.365$ \\
\hline Nervous system disorders & $4(2.2 \%)$ & $4(0.9 \%)$ & $P=0.241$ \\
\hline Dementia & $2(1.1 \%)$ & $0(0.0 \%)$ & $P=0.085$ \\
\hline
\end{tabular}

higher risk of new hip fractures, a study has not been conducted in this patient population. This is the first study conducted a prospective matched cohort study in Japanese osteoporosis patients with a history of hip fracture.

Patients on treatment with risedronate at the time of their initial visit and at the time of discharge were enrolled as the risedronate group. In the control group, patients receiving bisphosphonates at the time of discharge had discontinued treatment by the time of their initial visit. The patients who suffered a fracture even though they were on treatment with bisphosphonates might have been at higher risk.

In the present study, there was no significant difference in the incidence of adverse events between the risedronate group and the control group. However, gastrointestinal disorders were significantly more frequent in the risedronate group (7.1\%). Gastrointestinal disorders are a well-known adverse effect of bisphosphonates [25], and the results obtained in this study are considered to be within the expected range for Japanese patients based on previous data [26].

\section{Limitations}

This study was a prospective cohort study without randomization and blinding. Accordingly, comparability between the risedronate group and the control group was not complete. Therefore, demographic factors showing significant intergroup differences were adjusted by multivariate analysis to their influence on the results. Nevertheless, it is necessary to recognize this limitation when our results are interpreted.

Patients on treatment with risedronate at the time of their initial visit and at the time of discharge were enrolled as the risedronate group. In the control group, patients receiving bisphosphonates at the time of discharge had discontinued treatment by the time of their initial visit. The patients who suffered a fracture even though they were on treatment with bisphosphonates might have been at higher risk.

Future prospects

In order to provide appropriate therapy for osteoporosis, it is necessary to better define the characteristics of each drug, and large-scale long-term follow-up is required for accumulation of a sufficient number of events because of the relatively low incidence of hip fracture. A prospective international cohort study (Global Longitudinal Study of Osteoporosis in Women) [27] was started in 2006, with the aim of following approximately 60,000 women aged 55 or older for 5 years. Such efforts are expected to clarify the characteristics of drugs for osteoporosis therapy, including risedronate. 
Acknowledgments We are grateful to the following investigators and physicians for their contributions to our study.

Coordinating investigators: Masayuki Egashira and Hiroshi Enomoto (Department of Orthopaedic Surgery, Nagasaki University School of Medicine)

Physicians cooperating with the study: Yuji Sugitani, Narihiro Okazaki, Atushi Tagami, Shinichi Nakahara, Toshiyuki Kumashiro, Hidetoshi Tanaka, Akihiko Tokuda (Department of Orthopaedic Surgery, Nagasaki Rosai Hospital), Shuji Nakanishi (Department of Orthopaedic Surgery, Nagasaki National Hospital), Taketoshi Date (Department of Orthopaedic Surgery, St. Francis Hospital), Kazuyoshi Uchihashi, Kyota Nishifuru, Yoshihiro Nozaki, Ai Mori (Department of Orthopaedic Surgery, National Hospital Organization Nagasaki Medical Center), Masahiko Okumura (Department of Orthopaedic Surgery, Wajinkai Hospital), Toshihiro Sadamatsu (Department of Orthopaedic Surgery, Sadamatsu Hospital), Masaya Shiraishi, Takashi Tamai, Shoichi Kuba (Department of Orthopaedic Surgery, Nagasaki Prefecture Shimabara Hospital), Koichiro Tashiro (Department of Orthopaedic Surgery, Nagasaki Memorial Hospital), Tomoyuki Taura, Itaru Yoda, Kenichi Kidera (Department of Orthopaedic Surgery, Nagasaki Municipal Hospital), Shinji Adachi, Tomohiko Asahara, Masato Tomita, Kazuhiro Takahara (Department of Orthopaedic Surgery, Nagasaki Prefecture Tsushima Izuhara Hospital), Seiichirou Watanabe, Ritsu Tsujimoto (Department of Orthopaedic Surgery, Isahaya Health Insurance General Hospital), Kouichi Adachi, Chikara Miyamoto, Hirohumi Doukawa, Masakazu Murata (Department of Orthopaedic Surgery, Nagasaki Yurino Hospital), Masayasu Sugiyama (Department of Orthopaedic Surgery, Juzenkai Hospital), Goji Chiba, Kenshiro Takaki (Department of Orthopaedic Surgery, Nishiisahaya Hospital), Noboru Yamamoto, Kenji Kumagai (Department of Orthopaedic Surgery, Japan Seafarers Relief Association Nagasaki Hospital)

Affiliations are as at the time of conducting the study and are listed in random order.

Funding/support This study was supported by Takeda Pharmaceutical Co., Ltd., Osaka, Japan.

\section{Conflicts of interest None.}

Open Access This article is distributed under the terms of the Creative Commons Attribution Noncommercial License which permits any noncommercial use, distribution, and reproduction in any medium, provided the original author(s) and source are credited.

\section{Appendix 1: matching of the groups}

Matching parameters are shown below. Matching was regarded as satisfactory when all of the items for complete matching and three or more items for partial matching were obtained.

1. Items for complete matching (matching of all 3 items is required)

- Age: (1) 69 years or younger (2) 70-79 years (3) 80-89 years (4) 90 years or older

- Site of hip fracture: (1) lateral (2) medial

- Independence rating at the time of discharge: (1) independent walking or use of a cane (2) walker (3) wheelchair or bedridden
2. Items required for partial matching (matching of three or more items was required)

- Height: (1) less than $140 \mathrm{~cm} \mathrm{(2)} 140 \mathrm{~cm}$ or more - Body weight: (1) less than $50 \mathrm{~kg}$ (2) $50 \mathrm{~kg}$ or more - Postoperative period: (1) less than 3 months (2) 3 months to less than 6 months (3) 6 months or more - Presence/absence of vertebral body fracture: (1) absent (2) present (3) unknown

- Independence rating before injury: (1) independent walking or use of a cane (2) walker (3) wheelchair or bedridden

- Outpatient follow-up: (1) possible (2) impossible (3) unknown

\section{References}

1. Osteoporosis Prevention, Diagnosis, and Therapy. NIH Consensus Statement 2000 March 27-29; 17: 1-45

2. Kanis JA, McCloskey EV, Johansson H et al (2008) A reference standard for the description of osteoporosis. Bone 42:467-475

3. Looker AC, Melton LJ, Harris TB et al (2009) Prevalence and trends in low femur bone density among older US adults: NHANES 2005-2006 compared with NHANES III. J Bone Miner Res 25(1):64-7

4. Guidelines for prevention and treatment of osteoporosis. (2006) ed. Life Science Publishing Co., Ltd

5. Cooper C, Campion G, Melton LJ 3rd (1992) Hip fractures in the elderly: a world-wide projection. Osteoporos Int 2:285-289

6. Gullberg B, Johnell O, Kanis JA (1997) World-wide projections for hip fracture. Osteoporos Int 7:407-413

7. Orimo H, Yaegashi Y, Onoda T (2009) Hip fracture incidence in Japan: estimates of new patients in 2007 and 20-year trends. Arch Osteoporos 4:71-77

8. Prevention and management of osteoporosis. Report of a WHO scientific group. WHO Technical Report Series 921, 2003

9. Geusens P, McClung M (2001) Review of risedronate in the treatment of osteoporosis. Expert Opin Pharmacother 2:20112025

10. Fogelman I, Ribot C, Smith R et al (2000) Risedronate reverses bone loss in postmenopausal women with low bone mass: results from a multinational, double-blind, placebo-controlled trial. BMD-MN Study Group. J Clin Endocrinol Metab 85:1895-1900

11. Fukunaga M, Kushida K, Kishimoto $\mathrm{H}$ et al (2002) A comparison of the effect of risedronate and etidronate on lumbar bone mineral density in Japanese patients with osteoporosis: a randomized controlled trial. Osteoporos Int 13:971-979

12. Harris ST, Watts NB, Genant HK et al (1999) Effects of risedronate treatment on vertebral and nonvertebral fractures in women with postmenopausal osteoporosis: a randomized controlled trial Vertebral Efficacy With Risedronate Therapy (VERT) study group. JAMA 282(14):1344-1352

13. Reginster J, Minne HW, Sorensen OH et al (2000) Randomized trial of the effects of risedronate on vertebral fractures in women with established postmenopausal osteoporosis. Vertebral Efficacy with Risedronate Therapy (VERT) study group. Osteoporos Int 11:83-91

14. McClung MR, Geusens P, Miller PD et al (2001) Effect of risedronate on the risk of hip fracture in elderly women. Hip Intervention Program Study Group. N Engl J Med 344:333-340 
15. Masud T, McClung M, Geusens P (2009) Reducing hip fracture risk with risedronate in elderly women with established osteoporosis. Clin Interv Aging 4:445-449

16. MacLean C, Newberry S, Maglione M et al (2008) Systematic review: comparative effectiveness of treatments to prevent fractures in men and women with low bone density or osteoporosis. Ann Intern Med 148:197-213

17. Yoshihiro S, Tomohiro K, Kei S et al (2005) The prevention of hip fracture with risedronate and ergocalciferol plus calcium supplementation in elderly women with Alzheimer disease. Arch Inter Med 165:1737-1742

18. Yoshihiro S, Jun I, Tomohiro K et al (2005) Risedronate sodium therapy for prevention of hip fracture in men 65 years or older after stroke. Arch Inter Med 165:1743-1748

19. Investigational Committee for Osteoporosis Diagnosis Standard, Japanese Society for Bone and Mineral Research (2001) Diagnosis standard for primary osteoporosis (2000 revised edition). J Jpn Soc Bone Miner Res 8:76-82

20. De Laet C, Kanis JA, Odén A et al (2005) Body mass index as a predictor of fracture risk: a meta-analysis. Osteoporos Int $16: 1330-1338$
21. Chevalley T, Guilley E, Herrmann FR et al (2007) Incidence of hip fracture over a 10-year period (1991-2000): reversal of a secular trend. Bone 40:1284-1289

22. Melton LJ 3rd, Kearns AE, Atkinson EJ (2009) Secular trends in hip fracture incidence and recurrence. Osteoporos Int 20:687-694

23. Hagino H, Furukawa K, Fujiwara S et al (2009) Recent trends in the incidence and lifetime risk of hip fracture in Tottori, Japan. Osteoporos Int 20:543-548

24. Lyles KW, Colón-Emeric CS, Magaziner JS et al (2007) Zoledronic acid and clinical fractures and mortality after hip fracture. N Engl J Med 357:1799-1809

25. Peter CP, Kindt MV, Majka JA (1998) Comparative study of potential for bisphosphonates to damage gastric mucosa of rats. Dig Dis Sci 43:1009-1015

26. Kushida K, Kishimoto H et al (2002) Efficacy and safety of longterm treatment with risedronate in patients with osteoporosis and osteopenia. Osteoporos Jpn 10:85-97, in Japanese

27. Hooven FH, Adachi JD, Adami S et al (2009) The Global Longitudinal Study of Osteoporosis in Women (GLOW): rationale and study design. Osteoporos Int 20:1107-1116 